\title{
Influencia de la inversión en el subsector turístico sobre los niveles de empleo en Mérida, Yucatán
}

\author{
Carlos Leyva Morales* \\ Manuel Caro Encalada** \\ Hernán Pérez Cáceres ${ }^{* * *}$ \\ * Coordinador del Comité Asesor de Investigación \\ clmoral@tunku.uady.mx \\ ** Coordinador del Cuerpo Académico de Comercio \\ y Relaciones Internacionales \\ mcencala@hotmail.com \\ Profesores de la Facultad de Economía, \\ Universidad Autónoma de Yucatán \\ *** Ejecutivo de Prepago Nacional e Internacional \\ de los Hoteles RIU \\ lic.hernaneconomia@hotmail.com
}




\section{RESUMEN}

En el estudio se buscó determinar la relación entre la generación de empleos fijos y temporales del subsector turístico en la ciudad de Mérida, Yucatán y los niveles de inversión pública y privada. El análisis correlacional con el que se evaluó la relación entre las variables de interés, se basó en el desarrollo y aplicación de un modelo econométrico, confirmando su validez mediante la aplicación de pruebas de significación del coeficiente de correlación, la significación de la ecuación, la autocorrelación de las perturbaciones aleatorias, el supuesto de homocedasticidad de las perturbaciones aleatorias y la multicolinealidad. La comprobación de la relación econométrica establecida se basó en los principios económicos que las teorías sobre la inversión, los empleos y el impacto turístico proponen. Se confirmó que la variable independiente considerada en el modelo: inversión, explica adecuadamente a la variable dependiente: empleo, con lo que la primera parte de la hipótesis establecida, de que la generación de empleos fijos y temporales del subsector turístico en la ciudad de Mérida Yucatán es reducida debido a la existencia de escasos niveles de inversión pública y privada en las empresas turísticas locales, se valida estadísticamente; la validación económica de esta relación la sustenta los principios económicos planteados por Vellas (2004) respecto a que la tasa de ocupación está relacionada directamente con la rentabilidad de una inversión turística. En tanto que la evidencia empírica encontrada en los resultados del estudio sustenta que esto es ocasionado por las complicadas oportunidades para la obtención de créditos productivos a tasas preferenciales por parte de los inversionistas de este ramo en Mérida, con lo que se valida la segunda parte de la hipótesis de trabajo propuesta.

Palabras clave: Inversión, Empleo, Turismo, Mérida.

Clasificación JEL: C01, C21, E22, E24

Revista de Economía, vol. XXVII, núm. 75, segundo semestre de 2010. 


\section{ABSTRACT}

The study seeks to determine the relationship between the generation of fixed and temporary jobs in the tourism sector in the city of Mérida, Yucatán, and private and public investment levels. Correlation analysis that assessed the relationship between the variables of interest, based on the development and implementation of an econometric model, confirming its validity by applying tests of significance of the correlation coefficient, the significance of the equation, the auto correlation of random perturbations, random perturbations homocedasticidad assumed and the collinearity model. The econometric relationship checking was based on the economic principles proposed by theories about investment, employment and tourism impact. It was confirmed that the independent variable in the model: investment, adequately explains to the dependent variable: employment, so the first part of the established assumptions, that fixed and temporary tourist in the city of Mérida, Yucatán sub-sector employment generation is limited due to low levels of public and private local tourist enterprises investment, is statistically validated; economic validation of this relationship was supported by the economic principles raised by Vellas (2004) that the occupancy rate is directly related to the profitability of tourist investment. While empirical evidence founded in the results of the study sustains that this is caused by the complicated opportunities in obtaining productive credit at preferential rates for investors in this sector in Merida, so the second part of the proposed working hypothesis is validated.

Keywords: Investment, employment, tourism, Merida.

JEL Clasification: Co1, C21, E22, E24

Revista de Economía, vol. XXVII, núm. 75, segundo semestre de 2010. 



\section{INTRODUCCIÓN}

En el estado de Yucatán, el sector terciario es la actividad económica que en la actualidad predomina respecto a los sectores primario y secundario, ya que se manifiesta una terciarización de la economía al presentar las actividades de este sector un alto dinamismo y proporcionar un mayor nivel de valor agregado (tanto de bienes como de servicios) en comparación con los otros dos.

En la Figura 1 se puede observar que tanto en México como en el estado de Yucatán la gran mayoría de los establecimientos generales se dedican al sector terciario ( $87 \%$ y $75 \%$, respectivamente), registrando una cantidad a nivel nacional de 3, 441,225 empresas de un total de 3, 955,975 unidades en el año 2008 y a nivel estatal de 64,798 unidades económicas de un total de 85,844 negocios.

FIGURA 1. Cantidad de establecimientos en México y Yucatán por sector económico

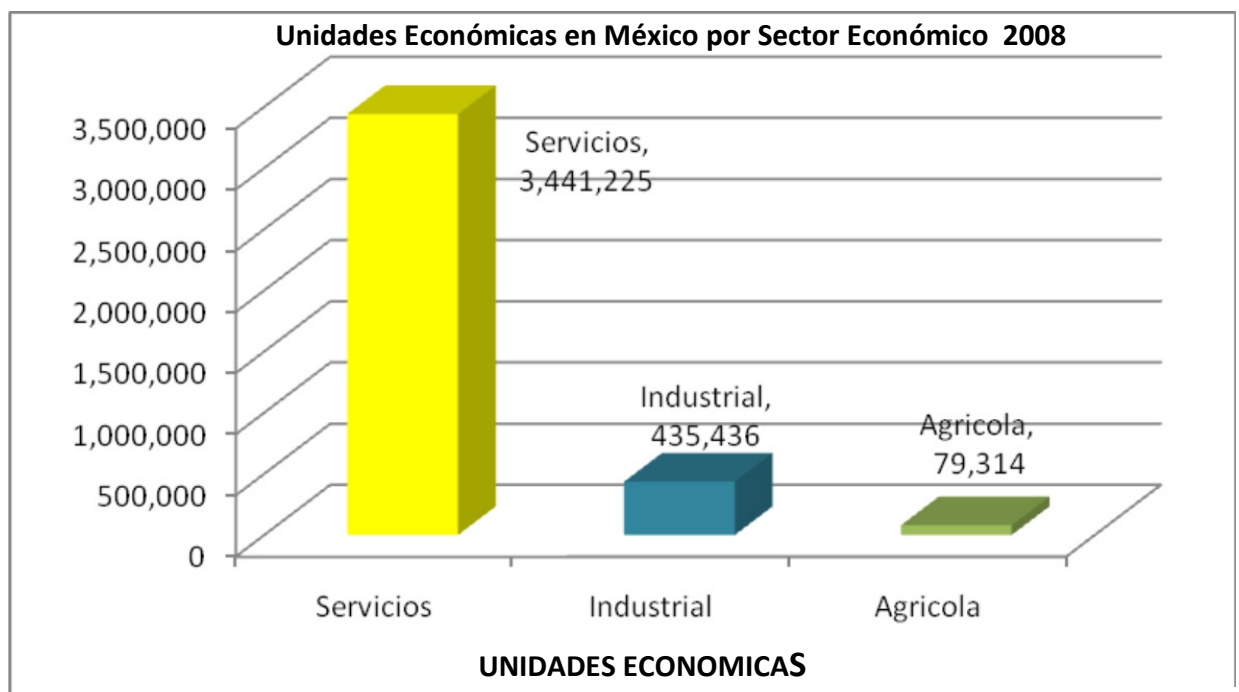

Fuente: Sistema de Información Geográfica. INEGI, 2010 


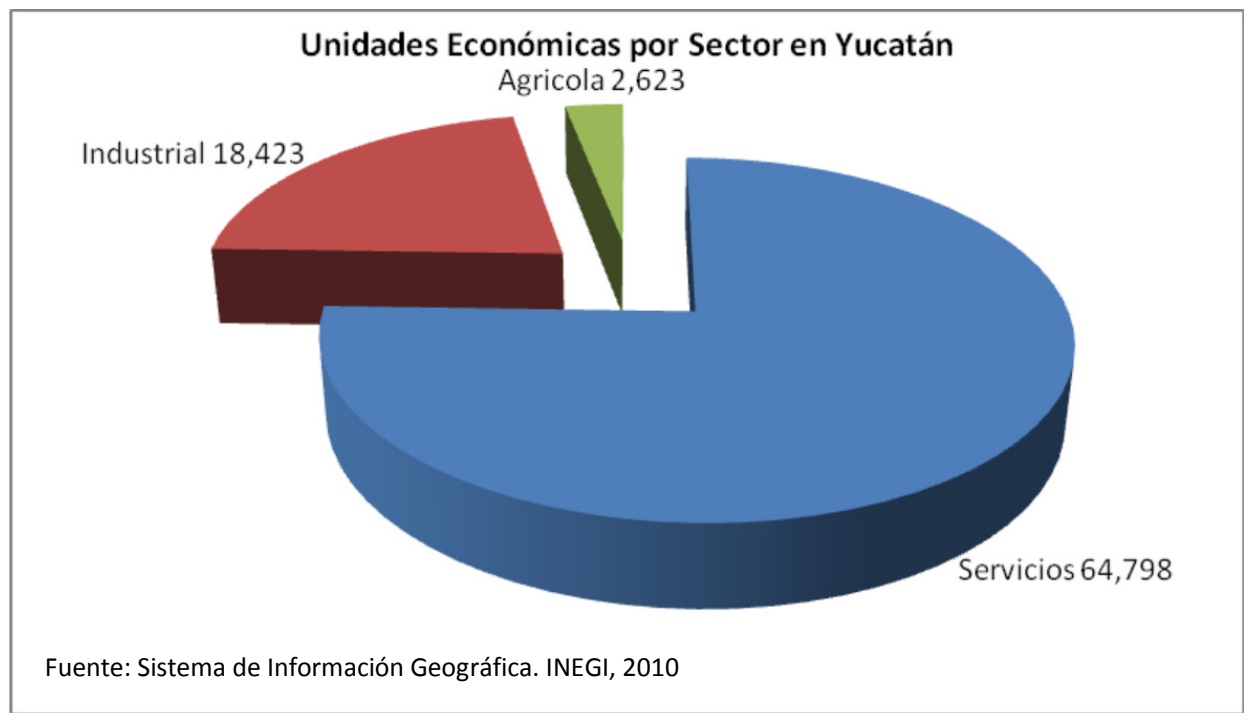

Por otra parte, como se puede apreciar en la Figura 2, si bien a nivel nacional el sector secundario es el que posee el mayor valor agregado que los otros dos sectores de la economía, al igual que en términos de la producción bruta total, siendo éste en el año 2008 de 2,924, 982,267 pesos, en el caso de Yucatán el sector terciario es el que mayor aportación tiene hacia este rubro, siendo ésta de 25, 528,018 pesos en ese mismo año, a pesar de que en cuanto a la producción total el sector que registró el mayor valor fue el secundario.

Esto es consecuencia de que las actividades terciarias insertan un mayor valor en la venta de sus bienes y servicios porque son destinados al consumidor final posteriormente de haber sido industrializados, como es el caso de la mayoría de los productos del sector terciario en la entidad.

Dentro del sector terciario, el turismo es la actividad que se erige como la principal fuente de divisas y por lo tanto es de relevancia para el crecimiento económico local de los países. Por ejemplo, en el caso de algunos países centroamericanos y de las Antillas, como las Bahamas, Puerto Rico, Costa Rica, etc., éstos, si bien son países en vías de desarrollo, gracias a su potencial turístico han logrado sobrevivir y destacar, aunque poseen una dependencia muy fuerte de esta actividad. 
FIGURA 2. Producción Bruta y Valor Agregado en México y Yucatán por sector económico

\section{Producción y Valor Agregado Bruto de los Sectores Económicos en México 2004}

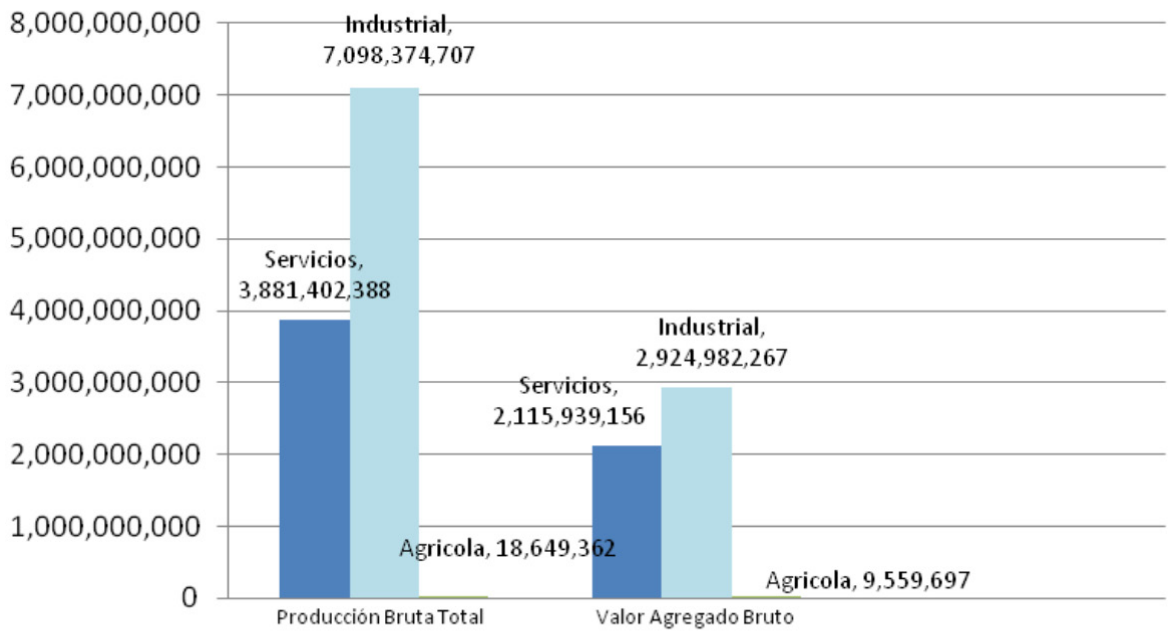

Fuente: INEGI. Cesos Económicos, 2009

\section{Producción y Valor Agregado Bruto de los Sectores Económicos en Yucatán}

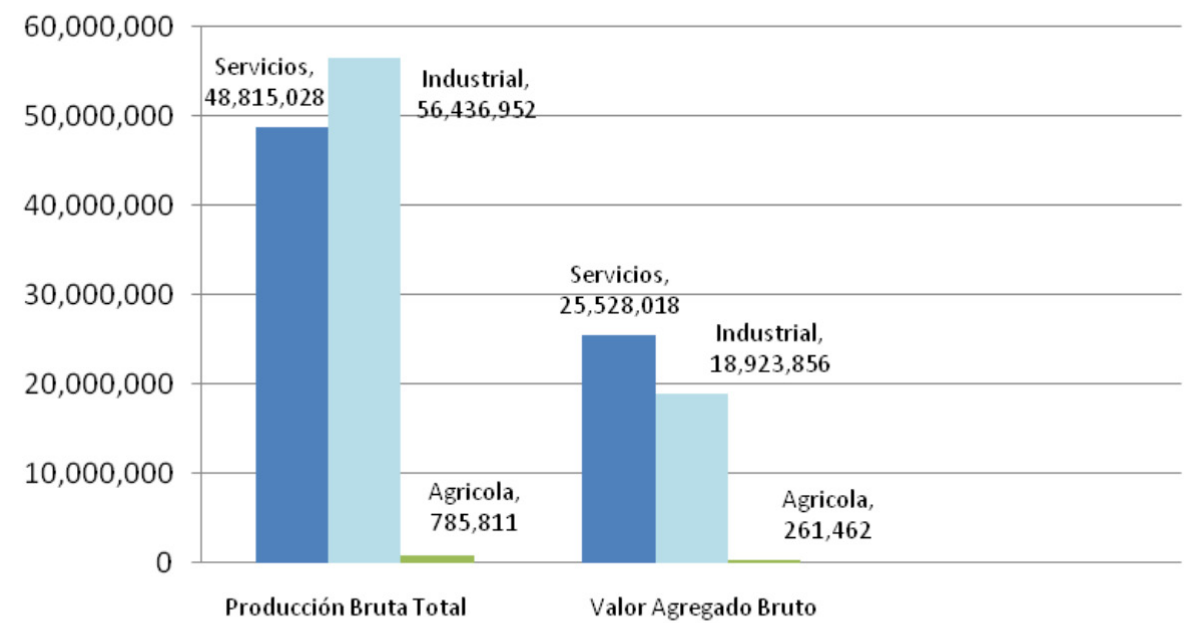

Fuente: INEGI. Cesos Económicos, 2009 
Para el periodo comprendido entre 2001 y 2006, los niveles de inversión privada en el sector turístico a nivel nacional fueron de $\$ 12,833.24$ millones de dólares en total, de los cuales se destinó la mayor proporción a los estados de Guerrero, Quintana Roo y Nayarit, por ser de los principales estados con importantes destinos turísticos en el país. Por su parte, en Yucatán la inversión privada en el sector turístico en ese mismo periodo fue de sólo \$61 millones de dólares, la cual representa apenas el $0.48 \%$ del monto total nacional del periodo 2001-2006 para dicha actividad, ocupando con ello el estado el vigésimo primer lugar en inversión turística a nivel nacional (Sectur, 2006).

Estas cifras indican que la mayor parte de la inversión privada destinada a las actividades turísticas se enfoca a los principales polos turísticos del país, lo cual repercute en la inadecuada proporción (o distribución) de los niveles de inversión hacia zonas cuya riqueza natural pudiera servir para desarrollar los destinos turísticos, situación que se presenta en Yucatán, así como en la creación de nuevos centros de atracción turística, lo cual también redundaría en beneficio del Estado.

Dado este contexto, la hipótesis de importancia por comprobar con este trabajo fue la siguiente: La generación de empleos fijos y temporales del subsector turístico en la ciudad de Mérida, Yucatán, es reducida debido a la existencia de escasos niveles de inversión pública y privada en las empresas turísticas, lo cual es ocasionado por las complicadas oportunidades de obtención de créditos productivos a tasas preferenciales para los inversionistas.

\section{METODOLOGÍA}

La presente investigación se basó en la combinación de dos tipos de diseño de comprobación de hipótesis no experimentales:

- El Transeccional Correlacional (mediante la recopilación de datos en un momento único) para poder explicar y analizar la relación existente entre la inversión y la generación de empleos en el subsector turístico de Mérida, Yucatán, y 
- El Longitudinal de Tendencia (mediante el análisis de las variables fundamentales sobre cambios realizados a través del tiempo en una población), el cual permitió analizar la evolución histórica de los niveles de inversión y empleo en el subsector turístico de la capital de la entidad.

Para obtener la información que permitió validar la hipótesis de investigación, se realizó la aplicación de las siguientes técnicas e instrumentos:

Revisión de literatura: Los datos nacionales y estatales sobre los indicadores de interés se obtuvieron principalmente de las publicaciones del Instituto Nacional de Estadística y Geografía, como son los Anuarios Estadísticos de Yucatán del periodo 2000-2008 y los censos económicos; de la Cuenta Satélite del Turismo del periodo 2000-2008; de estadísticas con respecto a los niveles de Empleo en Yucatán a través del Sistema de Cuentas Nacionales de México y del Banco de Información Económica. Las referencias bibliográficas se estructuraron y registraron en fichas bibliográficas, hemerográficas y de trabajo electrónicas.

* Encuesta Por muestreo: Se realizó investigación de campo en la que se aplicó una cédula de entrevista personal a los directivos o representantes de las empresas turísticas ubicadas en los principales destinos del mismo subsector en la ciudad de Mérida, Yucatán. La cédula de entrevista estuvo constituida por 52 preguntas, de las cuales 42 fueron preguntas cerradas y 9 preguntas abiertas. La cédula se dividió en 3 apartados: Información general, inversión en el subsector turístico y su financiamiento, y características del empleo en el subsector turístico.

La población o universo que se tomó en cuenta para la selección del tamaño de muestra fue la que corresponde a las actividades turísticas en el principal destino turístico del Estado: Mérida, Yucatán, tomados de los registros estadísticos de la Secretaría de Fomento Turístico Estatal (Secfomtur, 2008). Es importante señalar que estas actividades turísticas están conformadas por diversos giros como son: Hospedaje, Restaurantes, discos y bares, Agencias de viajes, Rentadoras de vehículos (arrendadoras), 
Líneas terrestres, Líneas aéreas, Museos, Artesanías, Banquetes, Guías de turistas, Consulados, Ecoturismo, Centros comerciales, Teatros y cines, Hospitales y clínicas, Escuelas de turismo, Casas de cambio, Marinas y Haciendas. Por ello para efectos de la investigación, se redujo esta población de actividades, considerando solamente las de mayor relevancia por concepto de una mayor relación con el turista y de la demanda de las mismas, en este caso las de: Hospedaje y de Agencias de viaje.

La muestra fue de tipo probabilística (Sampieri et al., 2007). Para los giros seleccionados dentro del municipio se aplicó el método de muestreo aleatorio estratificado, el cual fue obtenido mediante la separación de los elementos de la población en grupos que no presenten traslapes llamados estratos y posteriormente una selección de una muestra irrestricta aleatoria simple de cada estrato integrado (Scheaffer et al., 1987). Los estratos principales identificados en la ciudad de Mérida, Yucatán, y el tamaño de muestra obtenido fueron los siguientes:

- Mérida:

\begin{tabular}{|c|c|c|c|c|}
\hline $\begin{array}{c}\text { NÚMERO DE } \\
\text { ESTRATO }\end{array}$ & $\begin{array}{c}\text { TIPO } \\
\text { DE ESTRATO }\end{array}$ & $\begin{array}{c}\text { TOTAL } \\
\text { POBLACIONAL }\end{array}$ & MUESTRA & \\
\hline 1 & Hospedaje & 168 & 17 & $10 \%$ \\
\hline 2 & Agencias de viaje & 130 & 13 & $10 \%$ \\
\hline & & $\mathrm{N}=298$ & $\mathrm{n}=30$ & $10 \%$ \\
\hline
\end{tabular}

Cada una de las respuestas derivadas de la aplicación de la cédula, se clasificaron mediante códigos que permitieron un rápido manejo y registro de la información en el programa estadístico SPSS. Posteriormente, ésta se ordenó y analizó en esta hoja de cálculo. Para realizar los análisis de los resultados obtenidos, la obtención de los estimadores respectivos de las variables de estudio considerados (inversión y empleo) se basó en la aplicación de una ecuación que permitiera estimar la media y el total poblacional para cada una de las variables de interés.

El análisis correlacional con el que se evaluó la relación entre las variables de interés, se basó en el desarrollo y aplicación de un modelo 
econométrico en el que se pudiera observar el comportamiento de la inversión y el empleo. Para ello, se generó el siguiente modelo estadístico basado en la aplicación de la regresión lineal simple:

$$
\mathrm{Y}=\beta_{0}+\beta_{1} \mathrm{X}+\varepsilon
$$

Donde: $\mathrm{Y}=$ Cantidad de empleos generados en el sector turístico

$\mathrm{X}=$ Promedio de la inversión total realizada en el sector turístico

Este modelo permitió relacionar la variable independiente (inversión) con la dependiente (empleo), bajo los siguientes principios:

1. $\mathrm{My} / \mathrm{x}=\beta_{0}+\beta_{1} \mathrm{X}$ es el valor medio de la variable dependiente $\mathrm{Y}$ cuando el valor de la variable independiente es $X$.

2. $\beta_{0}$ es la ordenada en el origen. $\beta_{0}$ es el valor medio de $\mathrm{Y}$ cuando $\mathrm{X}$ es igual a 0 .

3. $\beta_{1}$ es la pendiente. $\beta_{1}$ es el cambio (cantidad de incremento o decremento) en el valor medio de $\mathrm{Y}$ asociado con un incremento de una unidad en X. Si $\beta_{1}$ es positiva, el valor medio de $\mathrm{Y}$ se incrementa cuando aumenta $\mathrm{X}$.

4. $\varepsilon$ es un término de error que describe los efectos sobre $Y$ de todos los factores que no son los valores de la variable independiente $\mathrm{X}$.

5 . La ordenada en el origen $\beta_{0}$ y la pendiente $\beta_{1}$ se denominan parámetros de regresión.

Con la información obtenida, se realizó la evaluación de la regresión propuesta, confirmando su validez mediante la aplicación de pruebas de significación del coeficiente de correlación (Prueba t de Student), la significación de la ecuación (Prueba $\mathrm{F}$ de Fischer), la autocorrelación de las perturbaciones aleatorias (Coeficientes de Durwin-Watson), el supuesto de homocedasticidad de las perturbaciones aleatorias y la multicolinealidad.

Las variables que se corrieron en las cuatro diferentes pruebas realizadas en el trabajo fueron las siguientes: 
Variables de la Regresión por Diferencias Anuales Respecto a Montos de Inversión y Empleos Generados en el Turismo en Mérida, Yucatán 2007-2008

\begin{tabular}{|c|c|c|}
\hline $\begin{array}{c}\text { No. de Empresas } \\
\text { Encuestas más importantes }\end{array}$ & Empleos generados & Inversión realizada \\
\hline 1 & 80 & $606,874,569$ \\
\hline 2 & 0 & $2,000,000$ \\
\hline 3 & 2 & 0 \\
\hline 4 & 2 & $1,260,000$ \\
\hline 5 & 0 & 0 \\
\hline 6 & 3 & 90,000 \\
\hline 7 & 1 & $-30,000$ \\
\hline 8 & 0 & 0 \\
\hline 9 & 5 & $-300,000$ \\
\hline 10 & 5 & $-400,000$ \\
\hline 11 & 6 & 80,000 \\
\hline 12 & 22 & 0 \\
\hline 13 & 9 & 0 \\
\hline 14 & 4 & 0 \\
\hline 15 & 0 & 0 \\
\hline 16 & 0 & \\
\hline
\end{tabular}

Fuente: Elaboración propia con base en entrevistas

Por último, para poder verificar la comprobación de la relación econométrica establecida se aplicó un análisis correlacional de Pearson y un análisis dinámico, y se observó si realmente se aceptaba o se rechazaba la hipótesis planteada, tomando en consideración los principios económicos que las teorías sobre la inversión (Dornbusch et al., 2002; Samuelson et al., 2006 y Tribe, 2000), los empleos (Vellas, 2004; García, 1987)) y el impacto turístico (McIntosh y Gupta, 1990; Acerenza, 1994 y, Hernández, 1991) proponen.

\section{RESULTADOS}

Características principales del turismo en México y su importancia en la economía nacional. El turismo, como actividad estratégica de la economía, es una herramienta de desarrollo compatible con 
los valores sustantivos de sus planes rectores ya que, debidamente planificado, contribuye al fortalecimiento y su difusión entre la comunidad turística. Sin embargo, en la práctica ésta ha sido una política selectiva en el caso de México, dirigiéndose hacia aquellos polos que cuentan ya con un determinado grado de desarrollo.

En el periodo 2003-2007 el turismo nacional tuvo una participación promedio en la economía del país de $8.4 \%$, el ramo que tuvo una mayor contribución al valor agregado de este subsector a lo largo del periodo fue el de Transporte, con 2.2\% en promedio (Figura 3). Le siguieron en importancia restaurantes, bares, centros nocturnos y alojamiento con 1.0\%; manufacturas con $0.9 \%$; comercio con $0.5 \%$; y el resto de las actividades con 2.8 por ciento (destacan en este segmento los tiempos compartidos que contribuyeron con $0.1 \%$ y las segundas viviendas con $0.2 \%$ ).

FIGURA 3. Participación en el Valor Agregado Bruto del Turismo Nacional

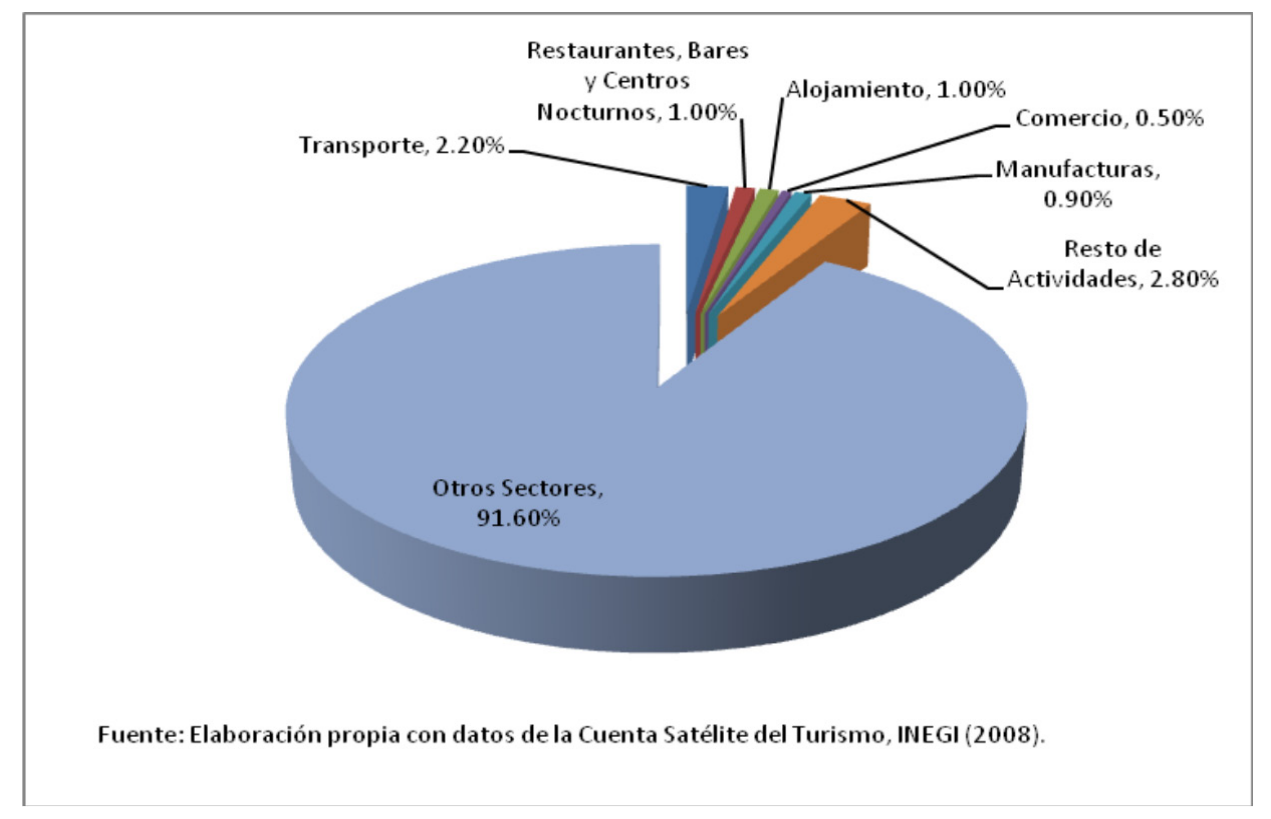

La composición de los bienes y servicios característicos y conexos, así como de las otras industrias turísticas en el Valor Agregado Bruto Turístico 
de 2003 a 2007 (Figura 4), redundó en 25.8\% del transporte, 12.3\% del alojamiento, $11.3 \%$ de restaurantes, bares y centros nocturnos, además de las manufacturas que también contribuyeron con $11.1 \%$, el comercio con $6.0 \%$ y el resto con $33.5 \%$ (destacan en este último rubro las segundas viviendas con $2.4 \%$ y los tiempos compartidos con $0.7 \%$ ).

Figura 4. Participación de la Oferta Turística Nacional

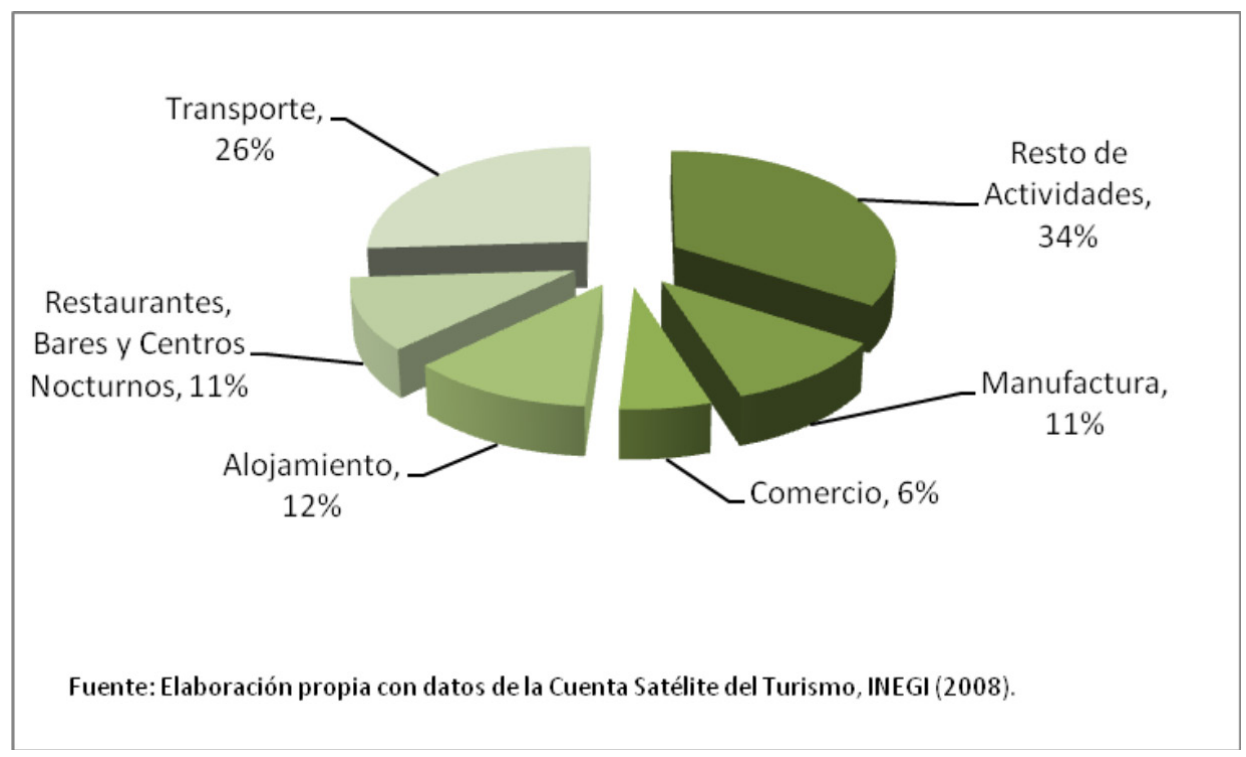

En el caso particular del Valor Agregado Bruto Turístico (Figura 5) se puede señalar que los servicios de alojamiento y restaurantes, bares y centros nocturnos representaron en este periodo $67.2 \%$ del sector 72 (servicios de alojamiento temporal y de preparación de alimentos y bebidas), el transporte de pasajeros 32.8\% del sector 48-49 (Transporte, correos y almacenamiento), los servicios de esparcimiento $27.7 \%$ del sector 71 (Servicios de esparcimiento, culturales y deportivos, y otros servicios recreativos), los servicios inmobiliarios $15.6 \%$ del sector 53 (Servicios inmobiliarios y de alquiler de bienes muebles e intangibles) y los bienes turísticos 7.6\% del sector 31-33 (Industria manufacturera). 
Figura 5. Composición de las Actividades Turísticas por Sector 2003-2007 (Participación porcentual del turismo por actividad)

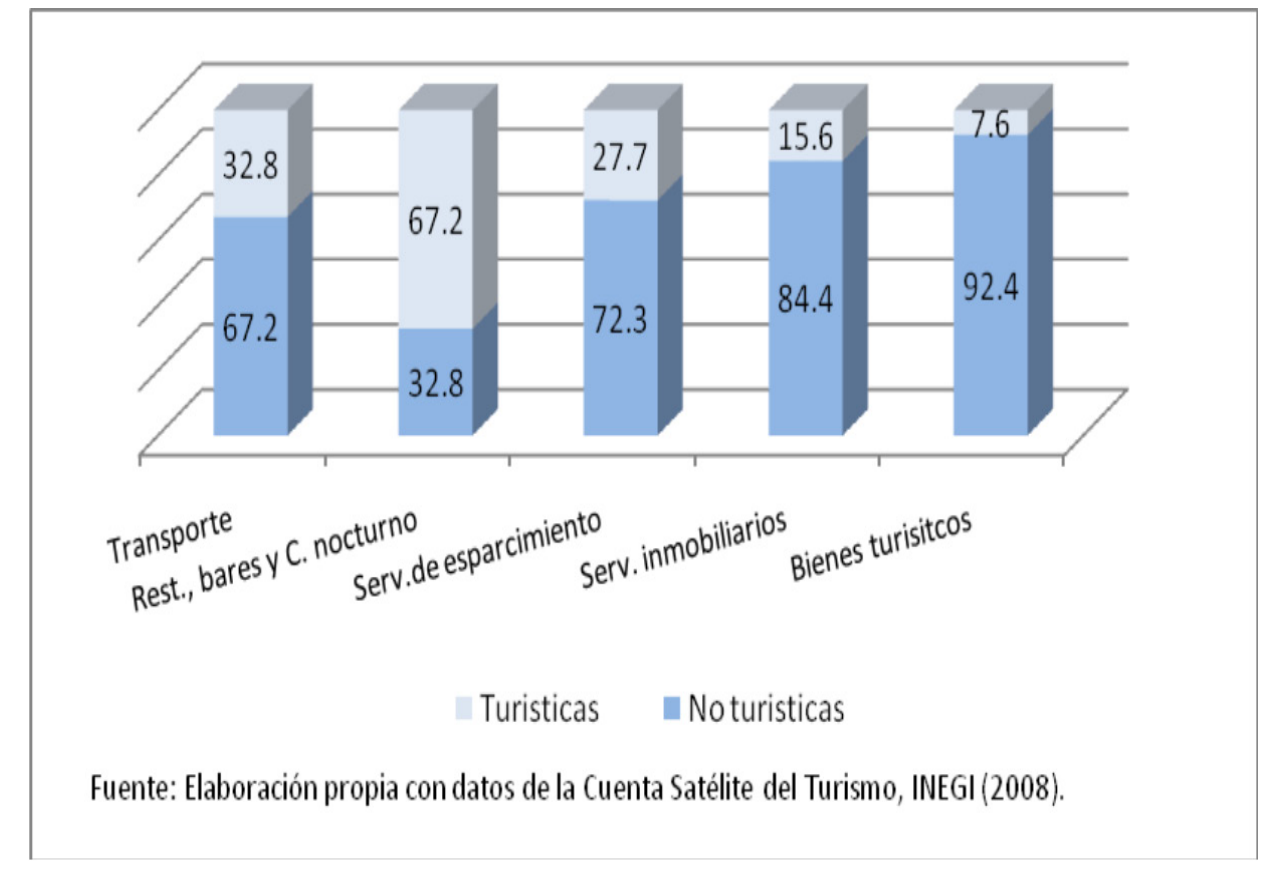

En lo que respecta al personal ocupado en esta actividad en México, éste se caracterizó durante el periodo 2003-2007, en lo general, por presentar cifras que denotan un comportamiento creciente; pasó de un total de 2,278 empleos en el año 2003 a 2,516 en 2007, año en que se registró el mayor número de empleos formales en el país en este subsector (Figura 6).

Con respecto a la participación del personal ocupado del sector turístico en el total del ocupado a nivel nacional (Figura 7), en 2003 se registró la menor participación de ésta con respecto a la población nacional total con un 6.6\%; sin embargo, en los años subsecuentes esta participación en general se puede decir que se incrementó, aunque manteniéndose con una participación casi constante de $6.9 \%$ en los años subsiguientes. 
Figura 6. Personal ocupado nacional en el subsector turístico (Miles de Personas)

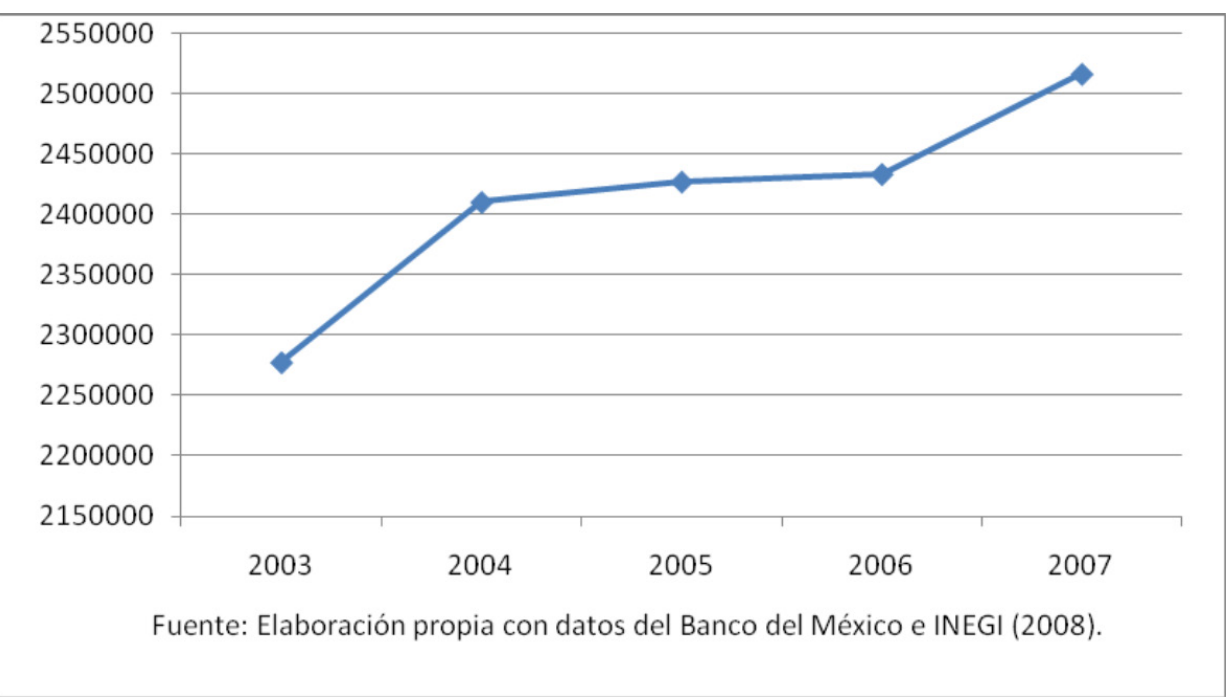

Figura 7. Participación del Personal Ocupado Turístico en la Economía Nacional

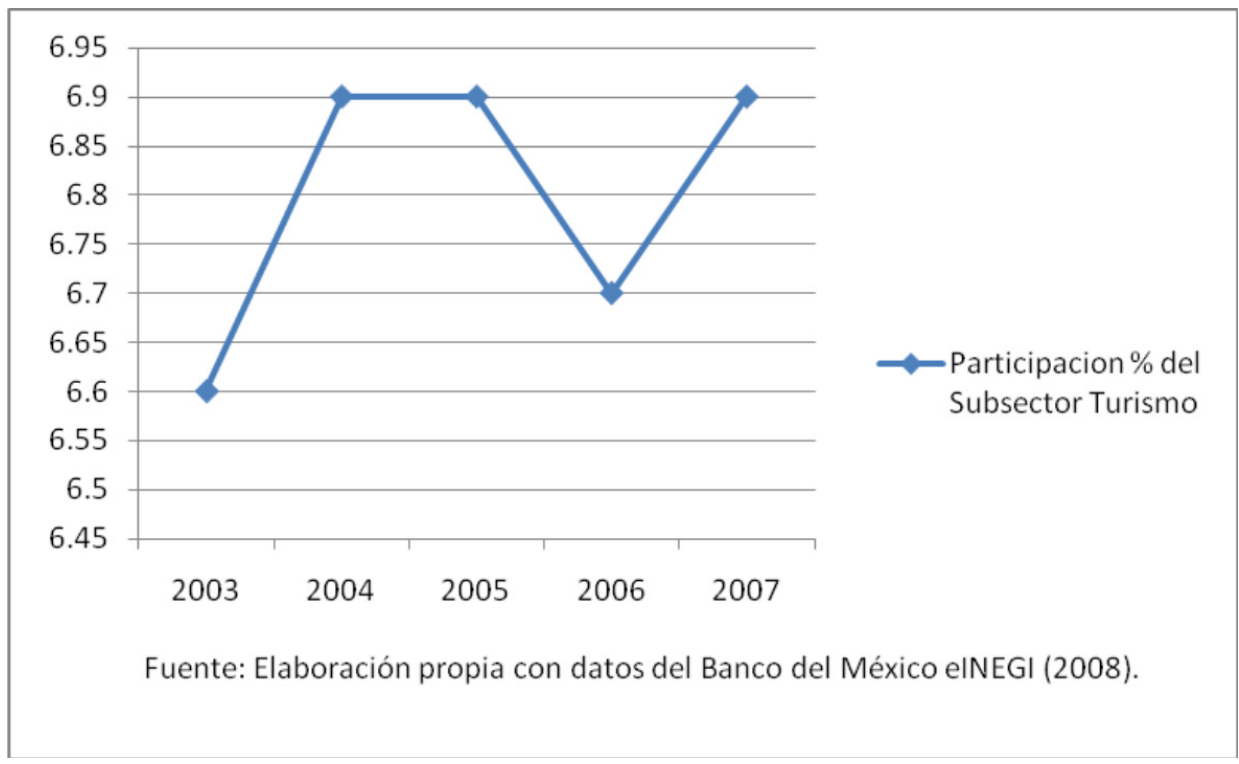


Por lo tanto, se puede decir que la participación de la población ocupada en el subsector turístico nacional se ha mantenido en los últimos años prácticamente sin cambio, como consecuencia de la falta de generación de empleos formales por las empresas turísticas existentes en el país, dada la preferencia por la contratación de trabajadores temporales para sus actividades durante las temporadas fuertes vacacionales.

Por consiguiente, se puede observar que la importancia del sector turístico en la economía nacional es radical ya que, como se ha evidenciado, se pueden obtener altos porcentajes del valor agregado para la economía del país, sobre todo de los ramos del transporte, alojamiento, restaurantes, bares y centros nocturnos, y teniendo en cuenta que son los servicios los que actualmente generan la riqueza de la nación. Se debe en consecuencia fomentar la generación de empleos formales en el subsector turístico del país, para aprovechar la tendencia creciente que ha observado la población ocupada nacional (Figura 8) y con ello se aumenten de igual forma los niveles de ocupación del sector turístico nacional, para que la distribución de los empleos en los sectores económicos de México sea equitativa y adecuada.

Figura 8. Personal ocupado a nivel nacional (Miles de Personas)

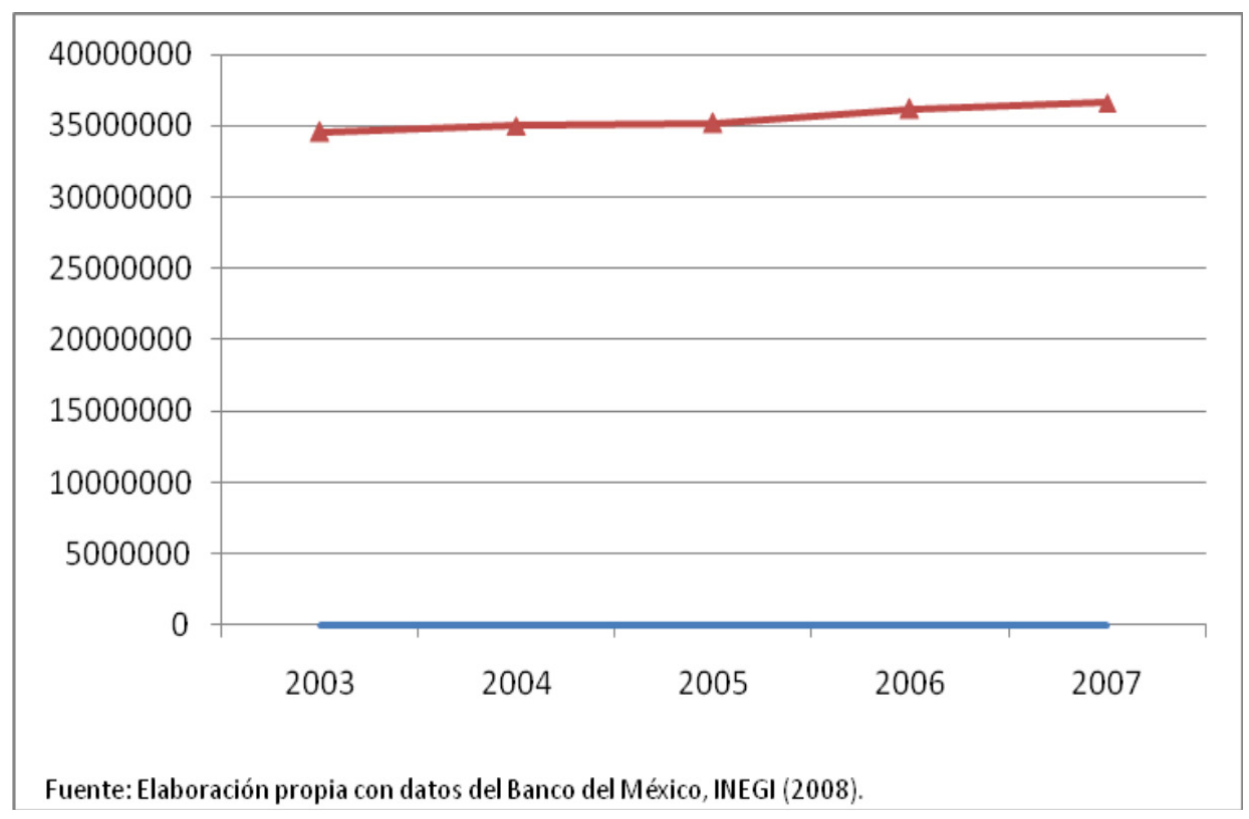


La Inversión en Turismo en la ciudad de Mérida, Yucatán. Para determinar los niveles de inversión que se realizan tanto a nivel nacional como estatal y local, se tiene que tomar en cuenta principalmente la Formación Bruta de Capital Fijo (FBCF), la cantidad de Unidades Económicas existentes (que son las que desempeñan las actividades turísticas), y por último, considerar el rubro de Inversión Total en el sector turístico para los 3 ámbitos, en el cual se incluye, además de los mencionados anteriormente, el valor total de los activos fijos y circulantes, las remuneraciones a trabajadores, las capacitaciones, etc., que lleva a cabo cada empresa turística. Los valores de los rubros mencionados anteriormente se pueden visualizar en el cuadro que a continuación se presenta para los tres niveles: local, estatal y nacional; éstos incluyen la inversión pública y privada en el subsector turístico. ${ }^{1}$

CUADRO 1. Niveles de Inversión General en Turismo en el ámbito local, estatal y nacional

\begin{tabular}{|c|c|c|c|}
\hline Nivel & Unidades Económicas & $\begin{array}{c}\text { Formación Bruta } \\
\text { de Capital Fijo } \\
\text { (Miles de Pesos) }\end{array}$ & $\begin{array}{c}\text { Inversión Total } \\
\text { (Miles de Pesos) }\end{array}$ \\
\hline NACIONAL & $2,260,430$ & $110,561,019$ & $178,110,423$ \\
\hline YUCATÁN & 48,174 & $1,587,456$ & $2,354,364$ \\
\hline MÉRIDA & 21,008 & $1,249,887$ & $1,817,256$ \\
\hline \multicolumn{4}{|l}{ Fuente: INEGI, 2004} \\
\hline
\end{tabular}

Así, se tiene en primera instancia, que las unidades económicas del estado y de la ciudad de Mérida apenas representaban $2.13 \%$ y $0.92 \%$, respectivamente, del total de las empresas turísticas nacionales existentes en 2004. Por su parte, la formación bruta de capital fijo estatal y local representaron $1.43 \%$ y $1.13 \%$, respectivamente, del monto nacional. En tanto que la inversión total estatal y local representaron $1.32 \%$ y $1.02 \%$, respectivamente, de la inversión nacional.

\footnotetext{
${ }^{1}$ Las cifras consideradas son las más recientes publicadas sobre estos indicadores.
} 
Particularizando el análisis, en la Figura 8, a continuación se puede apreciar que las unidades económicas turísticas de Mérida representaron 43.61\% de las unidades existentes a nivel estatal en el año 2004, lo cual significa que se han creado demasiadas empresas turísticas en esta ciudad en comparación con los municipios restantes del estado.

Figura 8. Comparativo de las Unidades económicas en el ámbito estatal y local

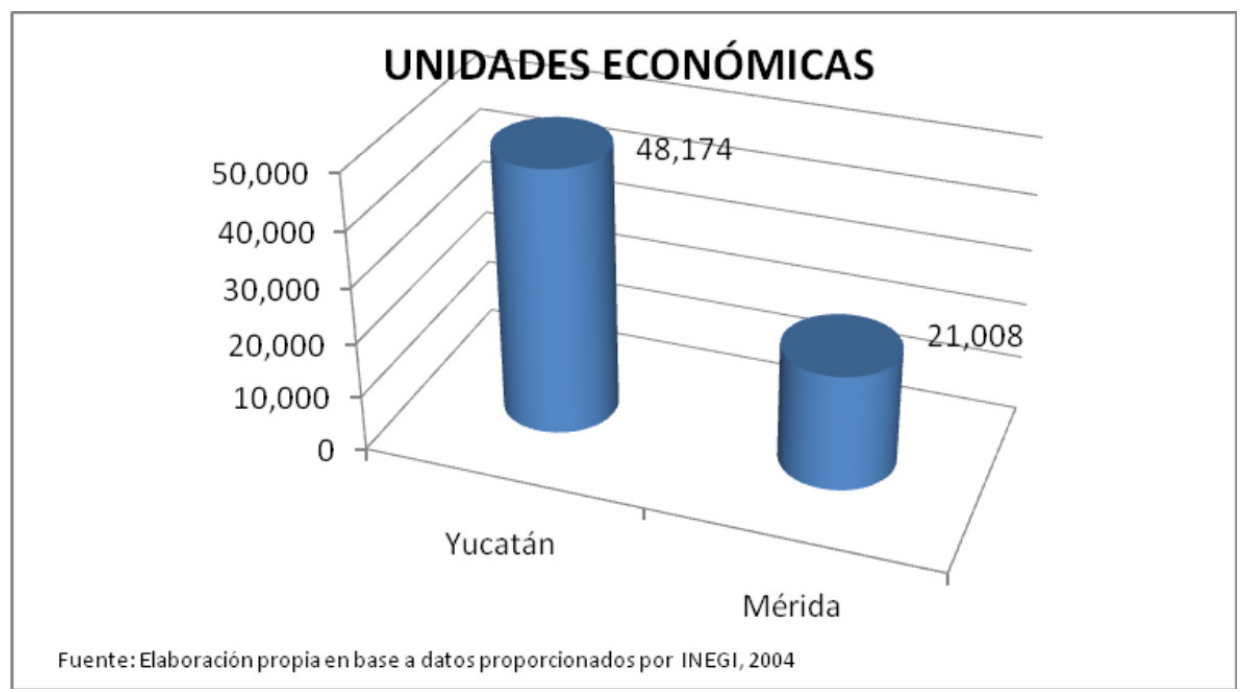

Por otro lado, la inversión en Formación Bruta de Capital Fijo para la ciudad de Mérida representó en 2004 casi 78.74\% de la inversión en Formación Bruta de Capital Fijo Estatal (Figura 9). Como se puede observar, Mérida invirtió en FBCF un monto de $\$ 1,249,887$ miles de pesos de un total invertido por Yucatán de $\$ 1,587,456$ miles de pesos.

En cuanto a la inversión en turismo se puede observar que a nivel local ésta presentó valores relativos cercanos a los de la inversión en turismo a nivel estatal, Mérida registró un porcentaje considerable de la inversión estatal, de 77.19\% (Figura 10). Es decir, que en Mérida se invirtió para 2004 un monto de $\$ 1,817,256$ miles de pesos en el sector turístico, en tanto que en Yucatán el total invertido fue de $\$ 2,354,364$ miles de pesos. 
Figura 9. Formación Bruta de Capital Fijo a nivel estatal y local

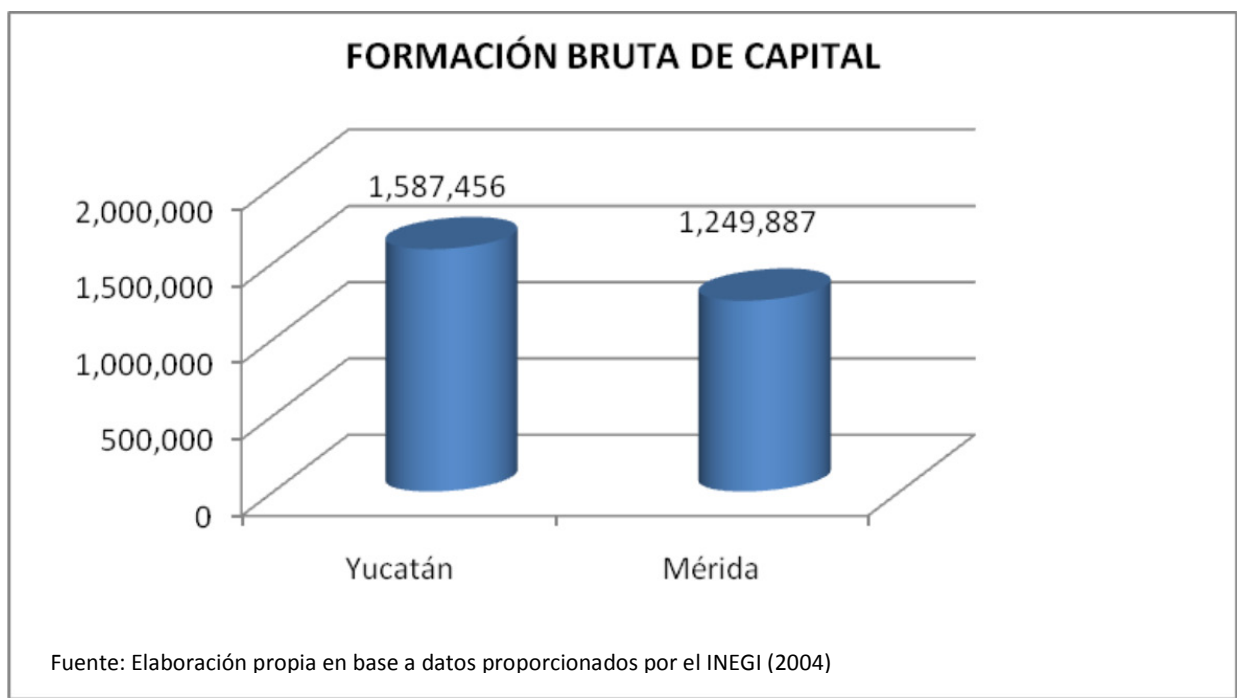

Figura 10. Inversión Total para el sector turístico

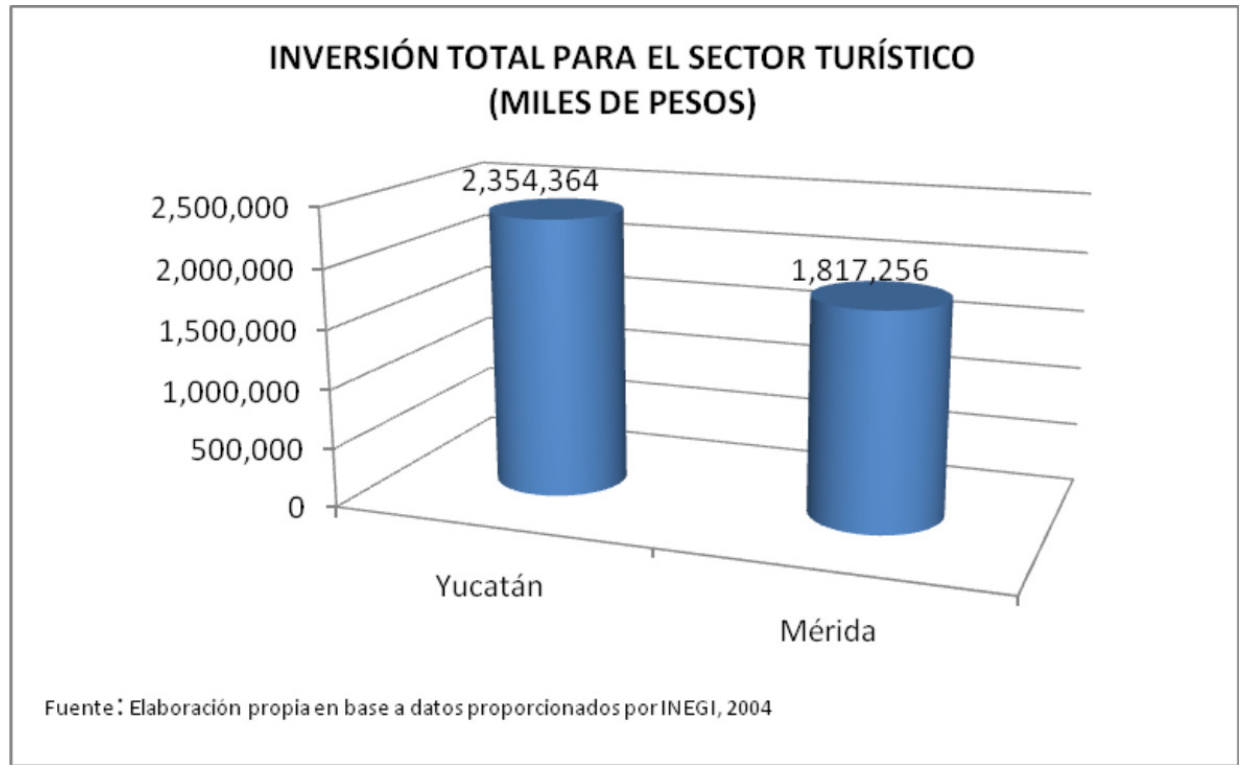

Las cifras más recientes indican que para 2007 se registró un promedio de inversión en el subsector del estado de \$357,142.86, lo cual dio 
lugar a que se ascendiera al noveno lugar a nivel nacional en materia de inversión en este subsector, en tanto que para 2008 ésta se incrementó en $\$ 68,023,841.03$, reflejo de la fuerte inversión que hizo el hotel Fiesta Americana en Mérida (Sectur, 2007).

La presencia de estos mínimos niveles de inversión privada en Yucatán, se explican por la ausencia de inversión pública en turismo en zonas importantes de riqueza natural y cultural del estado; no hay que olvidar que la inversión privada en este tipo de actividad sólo se da cuando es alentada por la inversión en infraestructura por el gobierno.

La riqueza natural y cultural que posee el estado, como son: las zonas arqueológicas prehispánicas, edificios coloniales, playas, reservas ecológicas, grutas, cenotes, etc., ${ }^{2}$ presente en diversos lugares en Yucatán en donde aún no se ha fomentado el turismo, entre éstos los puertos de: Sisal, Telchac, Chicxulub, etc., así como en aquellos municipios que poseen amplios cenotes en sus localidades, el caso de Tecom, Tizimín, entre otros, donde la información respecto a su existencia permanece en la población local y no se difunde a nivel nacional y mucho menos en el plano internacional; ${ }^{3}$ también se reproduce en la ciudad de Mérida, donde no se ha sabido aprovechar adecuadamente el turismo cultural y gastronómico, entre otros. No obstante lo anterior, los inversionistas privados prefieren otros destinos de inversión, encontrándose entre las principales causas de esto la detección de otros lugares con potencial turístico que posiblemente pudieran ser aprovechados, la existencia de dificultades para poder adquirir un financiamiento adecuado de las instituciones bancarias, así como por una escasa promoción de incentivos fiscales y una elevada incertidumbre

\footnotetext{
${ }^{2}$ De acuerdo con Acerenza (2000), el turismo se clasifica según el motivo en: Turismo rural, Turismo de sol y playa, Turismo cultural, Turismo, Gastronómico, Turismo religioso, Turismo idiomático, Turismo de negocio y Turismo de salud.

${ }^{3}$ La Organización Mundial del Turismo (OMT), con base en la definición de desarrollo sostenible establecido por el Informe Brundtland, afirma que: El desarrollo del turismo sostenible responde a las necesidades de los turistas y de las regiones anfitrionas presentes, a la vez que protege y mejora las oportunidades del futuro. Está enfocado hacia la gestión de todos los recursos de manera que satisfagan todas las necesidades económicas, sociales y estéticas, y a la vez que respeten la integridad cultural, los procesos ecológicos esenciales, la diversidad biológica y los sistemas de soporte de la vida.
} 
económica, representando todas ellas desventajas para la atracción de inversiones, principalmente de la extranjera, ${ }^{4}$ que podría beneficiar a la entidad mediante el incremento del poder adquisitivo de la comunidad cercana a los centros de atracción turística (Sectur, 2007), situación que no es exclusiva del estado de Yucatán.

Esto indica que el estado y sus principales destinos turísticos, como Mérida, aún requieren de mejores condiciones económicas para su funcionamiento como el mejoramiento de caminos, calidad de imagen para poder promocionar los potenciales turísticos adecuadamente, así como el innovar en el mejoramiento de los servicios públicos relacionados con los niveles de vida de la población de estos destinos (luz, drenaje, agua potable, etc.), entre otros rubros.

Los empleos del sector turístico en Mérida, Yucatán. Los empleos generados en 2004 en este subsector en el estado se pueden apreciar a continuación en el cuadro 2 en donde se realiza un comparativo numérico entre los tres ámbitos. Como se observa, de los empleos generados en los tres ámbitos, los de Yucatán apenas representaron el 1.95\% del generado a nivel nacional y la capital Mérida sólo 1.16\%. Esto significa que el Estado posee una muy reducida participación en la generación de empleos turísticos a nivel nacional, lo que implica que los empleos generados en Mérida, sean reducidos en proporción a los otros destinos turísticos de importancia del país.

Cuadro 2. Personal ocupado en el sector turístico en los ámbitos local, estatal y nacional

\begin{tabular}{|c|c|}
\hline Nivel & $\begin{array}{c}\text { Personal Ocupado Total } \\
\text { (Miles de Personas) }\end{array}$ \\
\hline NACIONAL & $11,192,736$ \\
\hline YUCATÁN & 217,767 \\
\hline MÉRIDA & 129,858 \\
\hline
\end{tabular}

Fuente: INEGI, 2004

\footnotetext{
${ }^{4}$ La mayoría de la inversión destinada al sector turístico estatal es realizada por inversionistas nacionales, la cual representó para 2007 94.15\%, en tanto que la extranjera, únicamente proveniente de Estados Unidos, fue equivalente a sólo 5.85\%.
} 
Por su parte, los empleos que se generaron en Mérida dentro del subsector turístico tienen una proporción significativa con respecto a los que se han creado en el ámbito estatal, ya que localmente representaron 59.63\% de los empleos generados en Yucatán en materia de turismo en 2004 (Figura 11).

Figura 11. Personal ocupado total en el subsector turístico en los ámbitos estatal y local

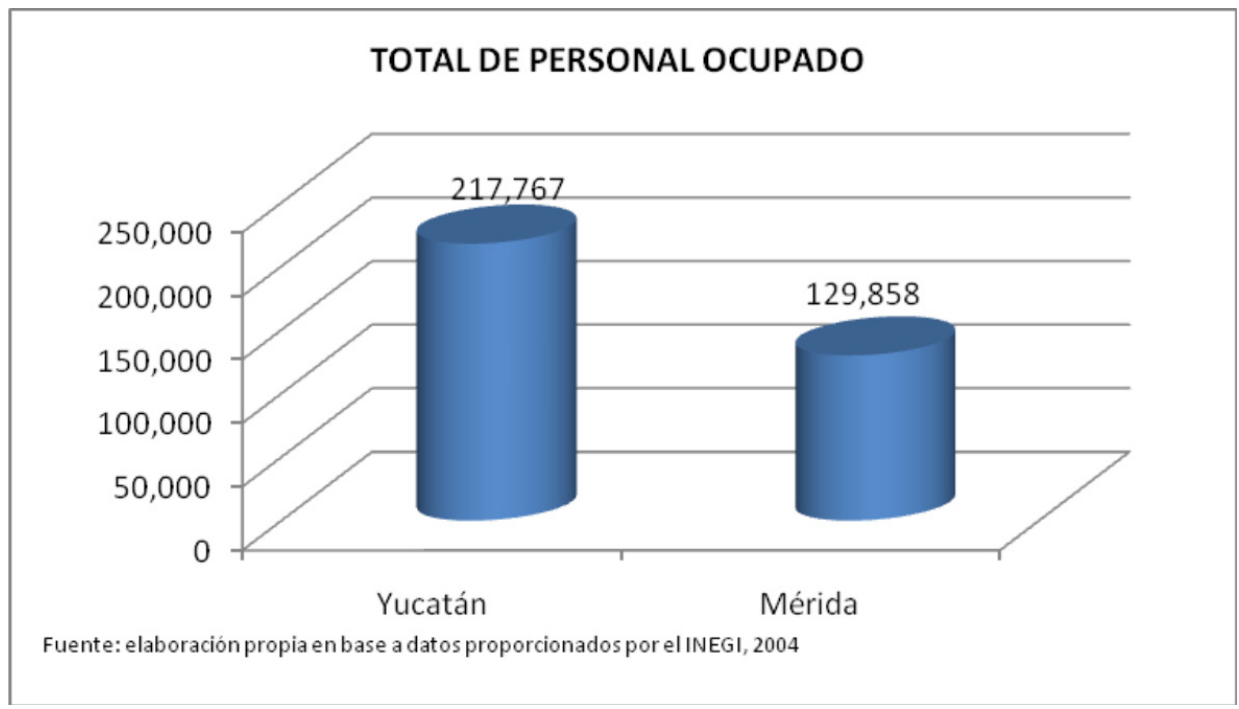

En lo general, los niveles de empleo registraron incrementos positivos en el subsector turístico yucateco, aunque esto se dio en forma más marcada en los centros de atracción turística ya existentes, como Mérida, Valladolid, Tinum y Celestún, dándose la mayor proporción de esta ocupación en el ramo hotelero (Secfomtur, 2008).

Por otro lado, $100 \%$ de los negocios relacionados con el turismo en Mérida se caracterizan porque en materia de empleo requieren de personal fijo en sus empresas, en tanto que $35 \%$ de los mismos, adicionalmente, requieren de personal para empleos temporales y sólo 21\% de ellos contrata a destajo o por productividad individual. Este tipo de estrategias (contrato temporal y a destajo) son utilizadas por los empresarios turísticos de la ciu- 
dad capital cuando solamente requieren de un mayor personal, principalmente durante las temporadas fuertes, como las vacaciones de verano e invierno en México, donde el personal fijo no es suficiente para satisfacer el incremento en la demanda de turistas egresivos (los que salen fuera del país) o receptivos (los que ingresan al país).

En temporada regular, los principales trabajadores que requieren los empresarios turísticos de Mérida son operativos y administrativos, 57\% de estos empresarios solicitan este tipo de empleos para las actividades diarias de la empresa; siendo su principal área que requiere nuevas contrataciones la de ventas principalmente, con $42.85 \%$ respecto al total de empresas turísticas.

Las contrataciones laborales nuevas son muy reducidas en todo el año para las empresas turísticas de Mérida (Cuadro 3), lo que las constituye en un foco de atención para los empresarios y el gobierno estatal.

Cuadro 3. Cantidad promedio de nuevos empleos en el sector turístico en Mérida

\begin{tabular}{|c|c|}
\hline Año & CANTIDAD PROMEDIO DE NUEVOS EMPLEOS \\
\hline 200 & 611 \\
\hline 200 & 76 \\
\hline 2008 & 17 \\
\hline
\end{tabular}

Fuente: Contrataciones anuales en Mérida, Yucatán estimadas en base a la encuesta aplicada.

El 85.7\% de los negocios turísticos en Mérida exigen una longitud en la jornada laboral de aproximadamente ocho horas diarias. En tanto que $78.57 \%$ de estos negocios invierten en capacitación anualmente, teniendo un gasto promedio de $\$ 41,085.00$ pesos anuales por este concepto.

Por último, se encontró que existen problemas en la difusión de los programas gubernamentales para apoyar a los trabajadores de las empresas turísticas de Mérida, ya que apenas 21.42\% conocen algunos de estos programas de apoyo y participan en los mismos. Esto indica que los empresarios del subsector turismo de Mérida desconocen los apoyos 
ofrecidos por el gobierno local, estatal y nacional, aunque hay que tener en cuenta que estos empresarios se niegan a la búsqueda de los mismos.

Financiamiento de las inversiones en turismo en Mérida, Yucatán y sus fluctuaciones respecto al tipo de cambio y tasas de interés. En materia de financiamiento, en la ciudad de Mérida Yucatán 71.42\% de los empresarios turísticos que se encuentran operando han estado invirtiendo en los últimos 6 años en sus negocios, quienes no han tenido dificultades para adquirir el financiamiento que requieren, ya que sus fuentes de financiamiento son propios, por lo que solamente gastan lo necesario para la operación de su empresa. Estos empresarios se han enfocado a invertir principalmente en mobiliario y equipo, que representó $57.14 \%$ del total invertido por estos negocios, y en segundo término, han invertido en capital humano mediante capacitaciones a su personal, $\mathbf{2 8 . 5 7 \%}$ de estas empresas.

Según el 35.71\% de los empresarios de este subsector, su frecuencia de inversión anual es de 2 veces al año debido a que no invierten constantemente; en tanto que $21.43 \%$ realizan inversiones una vez al año, sólo $14.28 \%$ de estos empresarios invierten más de dos veces al año. Se puede decir por consiguiente que la inversión en este subsector resulta escasa por el sector privado.

Respecto a los negocios turísticos en Mérida que financian sus inversiones, la mayoría lo realizan mediante financiamiento propio (64.28\%), en tanto que a través de préstamos bancarios o microcréditos, únicamente 14.28\% de este tipo de negocios utilizan estos planes de financiamiento con plazos de 2 a 3 años de pago y con tasas preferenciales (de aproximadamente de $8 \%$ a $13 \%$ anual) que les son otorgadas por su antigüedad en la adquisición de éstos. No obstante esto último, es importante señalar que la principal dificultad que presentan la mayoría de los empresarios turísticos de Mérida (64.8\%) en la obtención de financiamiento para invertir en sus empresas han sido las complicadas oportunidades que existen para la obtención de créditos productivos a tasas preferenciales en esta actividad. 
En lo que respecta al tipo de cambio en los negocios turísticos de Mérida, éste es manejado de manera fija, ya que $78.57 \%$ de estos negocios lo manejan de esa manera, donde la convertibilidad del dólar para todos los empresarios que invierten es de $\$ 12$ pesos por dólar. Por ende, sólo $21.42 \%$ de éstos respeta las fluctuaciones diarias del tipo de cambio y tienen que estar atentos de lo que acontece en el mercado cambiario. De esta manera, dado que el turismo depende de las fluctuaciones del tipo de cambio y de las tasas de interés, en el primero de éstos los empresarios turísticos de Mérida prefieren fijar los tipos de cambio en sus negocios para que no les perjudique durante sus operaciones comerciales y al realizar los gastos en inversión en sus negocios. En cambio, con las tasas de interés, éstos tratan de mantener un financiamiento propio para que no sufran de altibajos durante sus inversiones y puedan tener una adecuada actividad en el negocio.

Por otra parte, sólo $35.71 \%$ de los negocios del subsector turístico en Mérida consideran que las inversiones públicas realizadas para fomentar el subsector han sido eficientes, ya que así lo afirman (este porcentaje es muy reducido para considerarlo como eficiente). En tanto que para $\mathbf{2 8 . 5 7 \%}$ de estos empresarios el mismo gobierno no ha fomentado nada aun en cuanto a este tipo de inversiones, por lo que son neutrales al respecto, y sólo para $7.14 \%$ de éstos las inversiones públicas realizadas han sido deficientes respecto al fomento de esta actividad.

\section{Influencia de la inversión sobre los niveles de empleo en Mé-} rida, Yucatán. Análisis econométrico. La influencia de la inversión sobre los niveles de empleo en el subsector turístico en Mérida, Yucatán se evaluó a través de un análisis econométrico, considerando los datos obtenidos en el periodo 2000-2008, donde se realizaron cuatro pruebas estadísticas para determinar cuál modelo presentó los mayores datos estadísticos de impacto con los cuales validar la relación considerada. De ellas, se encontró que la mejor prueba del modelo de regresión fue la No. 2, donde se presentaron los mayores coeficientes de correlación (r) y de determinación (r2), y donde se aplicaron adecuadamente los principios económicos que las teorías consideradas establecen respecto a la inversión y al empleo (Figura 12). 
Figura 12. Resultados de la Regresión: Prueba \# 2 Resumen del modelo ${ }^{b}$

\begin{tabular}{|c|c|c|c|c|c|}
\hline Modelo & $\mathbf{R}$ & R cuadrado & $\begin{array}{c}\text { R cuadrado } \\
\text { corregida }\end{array}$ & $\begin{array}{c}\text { Error Tip. De la } \\
\text { estimación }\end{array}$ & Durwin/Wantson \\
\hline 1 & $.960^{\mathrm{a}}$ & .922 & .917 & 5.70503 & 1.63 \\
\hline
\end{tabular}

a variable dependiente EMP1

ANOVA $^{b}$

\begin{tabular}{|cl|c|c|c|c|c|}
\hline Modelo & \multicolumn{1}{|c|}{$\begin{array}{c}\text { Suma de } \\
\text { Cuadrados }\end{array}$} & gl & $\begin{array}{c}\text { Media } \\
\text { cuadrática }\end{array}$ & F & Sig \\
\hline 1 & Regresión & 5421.775 & 1 & 5421.775 & 166.581 & $.000^{\mathrm{a}}$ \\
& Residual & 455.663 & 14 & 32.547 & \\
& Total & 5877.437 & 15 & & \\
\hline
\end{tabular}

a Variables predictoras (constante) INV1

b Variable dependiente

Coeficientes $^{\text {a }}$

\begin{tabular}{|l|c|c|c|c|c|}
\hline \multirow{2}{*}{ Modelo } & \multicolumn{2}{|c|}{ Coeficientes no estandarizados } & $\begin{array}{c}\text { Coeficientes } \\
\text { tipificados }\end{array}$ & \multicolumn{2}{|c|}{} \\
\cline { 2 - 6 } & B & Error Tip. & Beta & t & Sig \\
\hline 1 (constante) & 3.911 & 1.473 & & 2.654 & .019 \\
INV1 & $1.253 \mathrm{E}-7$ & .000 & 960 & 12.907 & .000 \\
\hline
\end{tabular}

a Todas las variables solicitadas introducidas

b Variable dependiente EMP1

\section{Coeficientes $^{\mathrm{a}}$}

\begin{tabular}{|ll|c|c|}
\hline \multirow{2}{*}{ Modelo } & \multicolumn{2}{|c|}{ Estadísticos de colinealidad } \\
\cline { 3 - 4 } & & Tolerancia & FIV \\
\hline 1 & INV1 & 1.000 & 1.000 \\
\hline
\end{tabular}

a Variable dependiente EMP1

Variables introducidas/eliminadas ${ }^{\text {b }}$

\begin{tabular}{|c|c|c|c|}
\hline Modelo & $\begin{array}{c}\text { Variables } \\
\text { Introducidas }\end{array}$ & $\begin{array}{c}\text { Variables } \\
\text { eliminadas }\end{array}$ & Método \\
\hline 1 & INV $1^{\text {a }}$ & & Introducción
\end{tabular}

a Todas las variables solicitadas introducidas

b Variable dependiente EMP1

Diagnósticos de colinealidad $^{\mathrm{a}}$

\begin{tabular}{|c|c|c|c|c|c|}
\hline \multirow{2}{*}{ Modelo } & \multirow{2}{*}{ Dimensión } & & & \multicolumn{2}{|c|}{ Proporciones de Varianza } \\
\hline & & Autovalores & $\begin{array}{l}\text { Índice de } \\
\text { Condición }\end{array}$ & (Constante) & INV1 \\
\hline 1 & $\begin{array}{l}1 \\
2\end{array}$ & $\begin{array}{c}1.251 \\
.749\end{array}$ & $\begin{array}{l}1.000 \\
1.293\end{array}$ & $\begin{array}{l}.37 \\
.63\end{array}$ & $\begin{array}{l}.37 \\
.63\end{array}$ \\
\hline
\end{tabular}

a Variable dependiente EMP1 
De las pruebas de autocorrelación de las perturbaciones aleatorias (Durbin-Watson), de homocedasticidad y multicolinealidad realizadas, se encontró, primeramente, en la prueba de homocedasticidad mediante la prueba de Holt-White, una igualdad en la variabilidad de las perturbaciones aleatorias para este subsector en las variables consideradas. En cambio, por el hecho de que se tiene una ecuación lineal con una sola variable independiente, la prueba de multicolinealidad no se aplicó, ya que para ésta se necesita más de una variable para que sea efectiva.

Otro análisis que se realizó fue el de la de la distribución F de Fisher, la cual con un $\alpha=0.05$, es decir, 95\% de confiabilidad del modelo, arrojó una significancia cercana a o\% con una distribución F de 166.581, lo cual significa que las desviaciones estándar de las dos poblaciones normalmente distribuidas son iguales, de igual forma este resultado se puede interpretar como que las variables consideradas presentaron homocedasticidad, lo cual confirma lo expresado anteriormente respecto a esta prueba.

La ecuación obtenida al someterla a la prueba de autocorrelación de las perturbaciones aleatorias (Durbin-Watson) arrojó como resultado que la variable independiente (inversión) está fuertemente relacionada con la variable dependiente (empleo) con un valor de 1.63 entre ellas. Esto significa que la inversión tiene una estrecha relación con la generación de empleos en el subsector turístico de Mérida en un 1.63. Por ello, el estadístico de la regresión efectuada está distribuido en forma asintóticamente normal con media cero y varianza unitaria, y además se encuentra entre $(-1,96,+1,96)$, con $95 \%$ de confianza, por lo tanto esto implica que se puede rechazar la hipótesis nula de que no hay correlación de primer orden (positiva o negativa).

De igual manera, durante la regresión lineal se obtuvo un r2 ajustado de 0.917 con el que se entiende que los valores obtenidos de la regresión explican el 0.92 de la variable independiente (inversión) y que por tanto existe una fuerte relación. También se entiende que la variable independiente explica el 0.92 del comportamiento de la variable dependiente (empleo). Por lo tanto, la ecuación obtenida explica adecuadamente la 
relación entre ambas variables, y valida que existe estrecha influencia entre la inversión y el empleo generado dentro del subsector turístico de la ciudad capital de Yucatán.

La ecuación ponderada obtenida fue la siguiente:

$$
\mathrm{Y}=\beta_{0}+\beta_{1} \mathrm{X}+\varepsilon
$$

Empleos generados $=3.911+0.0000001253 \mathrm{I}+5.70503$

La interpretación de los valores de la ecuación anterior expresan que por cada millón de pesos que se invierta (entre inversión pública y privada) en turismo en Mérida sólo se generarán 0.125 nuevos empleos (fijos y temporales) en el subsector (con un nivel de significancia de $0.000^{a}$ para los valores considerados, es decir, 95\% de confiabilidad) y viceversa. Lo anterior confirma lo planteado por Vellas, 2004 respecto a que la tasa de ocupación está relacionada directamente y juega un papel importante en la rentabilidad de una inversión turística (recuérdese que existe una relación de dependencia entre la inversión y la rentabilidad y que adicionalmente una de las funciones de la inversión es que afecta a la producción a corto plazo a través de su influencia en la demanda agregada) y de que por tanto el factor turístico debe ser una inversión inteligente por la que se puede optar para generar nuevos empleos y brindar ocupación al mayor número de las personas que forman la Población Económicamente Activa de una zona geográfica. Por lo tanto, este es un valor que deben de considerar los generadores de las políticas públicas de fomento en este ramo en la entidad y en particular en la ciudad de Mérida, así como los agentes del sector privado que invierten en esta actividad económica.

Por último, es importante destacar que los resultados del ejercicio estadístico desarrollado permiten corroborar la relación denotada en apartados anteriores entre inversión y empleo en el estado en este ramo de la actividad económica, lo cual denota que la inversión en el sector turístico de una región es un factor importante que impacta positivamente en los otros sectores económicos de ésta, generando empleos tanto formales 
como informales en las diversas ramas de la economía. Sin embargo, esta inversión en el ramo del turismo no es el único determinante en éste en materia de generación de empleo, dado que también se puede generar por otros factores como: el gasto de gobierno en la formación de capital humano, las políticas públicas, el crecimiento económico de los otros sectores, el desarrollo global de la economía, entre otros (Samuelson, 2006, Dornbusch et al. 2002).

\section{CONCLUSIONES}

A nivel nacional en materia de turismo, Yucatán cuenta con una reducida participación en los montos invertidos debido a que el gobierno federal y los inversionistas privados (nacionales y extranjeros) se dirigen a los centros o polos turísticos de importancia del país y no toman en cuenta las potencialidades en materia de riqueza natural que existen en otras entidades susceptibles de fomentar, el caso del estado de Yucatán y, por ende, el de su ciudad capital Mérida.

No obstante lo anterior, se determinó que Mérida es la ciudad que recibe los mayores beneficios en cuanto a inversión total y Formación Bruta de Capital Fijo por concepto de turismo en la entidad, representando $77 \%$ y $79 \%$, respectivamente, del monto total ejercido en 2004, por consiguiente es muy escaso lo que se asigna respecto a estos rubros para los demás municipios del interior del estado. Por lo que se puede decir que Yucatán enfoca el crecimiento y desarrollo de su turismo solamente en la ciudad de Mérida, por lo que el problema en materia de focalización de la inversión en turismo se presenta no sólo a nivel nacional sino que también se reproduce en el estado. Esto indica que el subsector turístico estatal y sobre todo el de Mérida no presentan niveles de inversión adecuados (al menos del $5 \%$ anual se recomienda) en comparación con otros estados de la República. La razón de esta falta de una distribución adecuada de la inversión en el ramo turístico en el estado se explica en que aún no se ha dado una adecuada propaganda de las riquezas naturales locales ni se ha realizado un fomento al turismo de Yucatán en el país. 
Por otra parte, la mayoría de la inversiones realizadas en el turismo en la ciudad capital de Yucatán son hechas por las empresas del ramo con financiamiento propio (la gran mayoría de estos negocios invierten en los diferentes rubros de sus empresas, principalmente en materia de mobiliario y equipo), y no han considerado incrementar sus niveles de inversión a través de la obtención de créditos. Ello implica que estos negocios se han desligado de la información sobre programas gubernamentales o privados de apoyo a las inversiones de las pequeñas y medianas empresas de este ramo, y por lo tanto, que existen dificultades para estos inversionistas en la adquisición de financiamiento para el desarrollo de su actividad en el plano local, tanto por la falta de información como de tasas preferenciales.

Otro punto importante en el análisis realizado fue la cantidad de empleos generados anualmente en el subsector turístico de Mérida, el cual resultó relativamente bajo de acuerdo a las cifras obtenidas. Esto implica la existencia de un mayor nivel de desempleo en este ramo en la ciudad capital de Yucatán, principalmente por la falta de oportunidades laborales que bien pudieran ser aprovechadas por el subsector y con ello fomentar la generación de empleos en el estado. Adicionalmente, la evidencia empírica presentada es que se han creado pocos empleos nuevos en este ramo en la ciudad, principalmente porque los empresarios turísticos no se han dedicado realmente a invertir en sus empresas por este concepto, solamente lo hacen para las necesidades diarias de su actividad y durante las temporadas fuertes de la misma; por las escasas oportunidades de crecimiento en el subsector por parte de los empresarios locales; además de que el gobierno no ha fomentado adecuadamente el potencial que tiene Mérida en todos sus ámbitos turísticos, ni ha podido invertir en la infraestructura adecuada para generar las oportunidades de empleo necesarias, en consecuencia algunos de estos empresarios han dejado de expandirse y se han enfocado solamente al mercado local. Por lo tanto, se puede decir que en la ciudad de Mérida, Yucatán, existe una falta de adecuados planes de financiamiento de las inversiones de los negocios turísticos y de interés por parte de los empresarios de este ramo en obtenerlos, para así poder incrementar sus gastos de inversión en sus negocios, y con ello, de requerir de una mayor cantidad de personal para atender las nuevas exigencias del mercado que se les presenten, lo cual conllevaría a generar más empleos formales en este ramo. 
Dado que el principal propósito del estudio fue demostrar que en materia económica, en efecto, los empleos que se pueden generar por el subsector turístico en Mérida dependen en gran medida de la inversión pública y privada realizada en este ramo tan importante. $\mathrm{Al}$ respecto, se determinó que el turismo en la ciudad de Mérida, Yucatán, ha presentado serios problemas respecto a los niveles de inversión realizados en este subsector, los empresarios están poco informados y desinteresados de las oportunidades de inversión, así como sometidos a un presupuesto muy apretado si lo realizan por cuenta propia, y por ende en la generación de empleos dentro del mismo, sólo 50\% de los empresarios turísticos consideran que los empleos generados fueron por efecto de los incrementos en los niveles de inversión de sus negocios. Esto se comprobó a través del modelo econométrico obtenido donde los valores en las diferencias de un año con otro con respecto al número de empleos generados y los montos invertidos en Mérida, Yucatán, en el ramo turístico resultaron estrechamente enlazados en forma positiva y directa, ya que las pruebas de autocorrelación de las perturbaciones aleatorias (Durbin-Watson de 1.163), de $\mathrm{r}^{2}$ (0.917) y de homocedasticidad del modelo así lo comprobaron).

Por lo tanto, se confirma que la variable independiente considerada en el modelo, inversión, explica adecuadamente a la variable dependiente, empleo, con lo que la primera parte de la hipótesis establecida, de que la generación de empleos fijos y temporales del subsector turístico en la ciudad de Mérida, Yucatán, es reducida debido a la existencia de escasos niveles de inversión pública y privada en las empresas turísticas locales, se valida estadísticamente; la validación económica de esta relación la sustenta los principios económicos planteados por Vellas (2004) respecto a que la tasa de ocupación está relacionada directamente con la rentabilidad de una inversión turística, por lo que el factor turístico debe ser una inversión inteligente por la que se debe de optar para generar nuevos y mayores empleos. En tanto que la evidencia empírica señalada en los resultados del estudio sustenta que esto es ocasionado por las complicadas oportunidades en la obtención de créditos productivos a tasas preferenciales por parte de los inversionistas de este ramo en Mérida, con lo que se valida la segunda parte de la hipótesis de trabajo propuesta y por consiguiente ésta es aceptada en forma completa. Sin embargo, es también 
importante señalar que existen otros factores determinantes en materia de generación de empleo, de entre los cuales el de las políticas públicas de apoyo al desarrollo de este subsector podría jugar un papel relevante en la inversión por parte del sector privado estatal, lo que potenciaría la generación de empleo dentro del ramo turístico de Yucatán con su correspondiente efecto multiplicador dentro del mismo.

\section{BIBLIOGRAFÍA}

Acerenza, Miguel Angel. (2000) Administración del turismo, conceptualización y organización. Volumen 1. Ed. Trillas. México.

Banco de México: www.banxico.com.mx

Bowerman, Bruce L., Connell, Richard T., Koehler, Anne B., (2007), Pronósticos, series de tiempo y regresión: Un enfoque aplicado, Editorial Thomson, 4ta edición, México.

Caro Encalada, Manuel J., (Primer Semestre 2008), "El rol de las tecnologías de la información en la empresa hotelera”, Revista de Economía, Edición de la Facultad de Economía de la Universidad Autónoma de Yucatán, Año XXV, Volumen I, No. 70.

De la Torre, Oscar, (1994), El turismo: fenómeno social, Editorial Fondo de Cultura Económica, Primera edición, México, pp. 13-27.

Dornbusch, Rudiger, Fisher, Stanley, Startz, Richard, (2002), Macroeconomía, Editorial Mc Graw Hill, Octava edición, España, pp. 143165 .

FAO en http://www.fao.org/sard/static/leader/es/biblio/tourism.pdf

García Villa, Adolfo, (1987), Planificación y evaluación del turismo, Editorial Limusa, Primera edición, México, pp. 9-27. 
Greene, William H., (2000), Análisis econométrico, Editorial Prentice Hall, 3era Edición, España.

Hernández Díaz, Edgar Alfonso, (1991), Planificación turística: un enfoque metodológico, Editorial Trillas, Primera edición, México, pp. 9-18.

INEGI (2004), Sistema Automatizado de Información Censal versión 5.0, Instituto Nacional de Estadística y Geografía, México.

Martínez García, Jorge B., (Diciembre 1970), El turismo en el desarrollo económico (El caso de México), Tesis de Licenciatura, Monterrey, Nuevo León, México.

McIntosh, Robert, Gupta, Shashikant, (1990), Turismo: planeación, administración y perspectivas, Editorial Limusa, Primera edición, México, pp. 22-25, 221, 263, 284-286.

OMT, Compendium of Tourism Statistics, Edition 2006, Madrid and New York, pp. 265-325.

OMT, (2006), Yearbook of Tourism Statistics, Madrid and New York, pp. $357-425$.

Samuelson, Paul A., Nordhaus, William D., (2006), Macroeconomía con aplicaciones a Lationamérica, Editorial Mc Graw Hill, decimoséptima edición, México, pp. 137-142, 348-361, 365-382.

Scheaffer, Richard L., Mendenhall, William, Ott, Lyman, (1987), Elementos de Muestreo, Editorial Iberoamérica, México.

Secfomtur, Junio de 200, Programa estratégico de Promoción Turística: Análisis del crecimiento de la oferta turística en el Estado de Yucatán, Gobierno del Estado de Yucatán, Mérida, Yucatán, México. 
Sectur, 2006, La inversión privada en el sector turístico 2001-2006, Gobierno Federal.

Sectur, 2006, La inversión privada en el sector turístico 2007, Gobierno Federal.

Tribe, John, (2000), Economía del ocio y el turismo, Editorial Síntesis, Segunda edición, España, pp. 285-314.

Vellas, Francois, (2004), Economía y política del turismo internacional, Editorial Síntesis, Madrid, España, pp. 119 - 131, 148-152.

www.inegi.org.mx/est/contenidos/espanol/proyectos/censos/ce2009/ res_oportunos/RO-09_Analisis_comparativo_2004_2009.pdf 